\title{
ARTES DA EXISTÊNCIA E AS VIDAS INFAMES $^{1}$
}

Regiane Lorenzetti Collares (UFCA) ${ }^{2}$

regiane.collares@ufca.edu.br

Luis Celestino de França Júnior (UFCA) ${ }^{3}$

luis.celestino@ufca.edu.br

Resumo: Este artigo objetiva, a partir das considerações de Michel Foucault sobre a dimensão de uma estética da existência, relacioná-la às vidas infames, em dois planos que parecem se vincular, a saber, primeiro, de dar destaque às vidas obscurecidas que apenas foram iluminadas quando colocadas como alvos de discursos empreendidos com a finalidade de classificação, controle e exclusão; segundo, da possibilidade de experiências transformadoras no que diz respeito às subjetividades marginalizadas. Examinaremos então em que medida a pesquisa foucaultiana portaria a virtualidade de um deslocamento a um só tempo estético e ético, da modificação de um modo de vida, de um estilo de existência. Uma vez reconhecendo a dimensão estética em Foucault vinculada à arte de existir, pretendemos então tecer um texto que também se componha com as considerações do filósofo da estética Étienne Souriau, apresentadas no livro As Existências Mínimas, por David Lapoujade, no sentido de que os dois pensadores franceses parecem confluir na mesma direção no que liga a arte às transformações de si, isto é, ambos elaboram uma compreensão da estética interseccionada aos modos de existência, buscando tematizar de que modo as vidas que mesmo privadas do direito de existir, podem ainda encontrar espaços de criação e transformação.

Palavras-chave: Arte; Existências Mínimas; Transformação de Si; Estilos de vida.

\footnotetext{
${ }^{1}$ Recebido: 22-07-2020 / Aceito: 07-11-2020 / Publicado online: 15-04-2021.

${ }^{2}$ Professora Assistente da Universidade Federal do Cariri (UFCA), Juazeiro do Norte, Ceará, Brasil. Orcid: https://orcid.org/0000-0002-3066-1163

${ }^{3}$ Professor Adjunto da Universidade Federal do Cariri (UFCA), Juazeiro do Norte, Ceará, Brasil. Orcid: https://orcid.org/0000-0003-0312-5063.
} 


\section{INTRODUÇÃO}

Pensar em uma estética em Foucault ligada à existência é também se vincular a posições que envolvem resistência e luta. Entendemos de antemão que resistir equivale sobretudo a criar outros espaços para que as vidas possam se deslocar das armadilhas de assujeitamento e conquistar novos modos, estilos. Se a estética da existência identificada por Michel Foucault na Antiguidade constituía-se "por um esforço para afirmar a própria liberdade e dar à sua própria vida uma certa forma na qual podia se reconhecer e ser reconhecido por outros e onde a posteridade mesma poderia encontrar como exemplo" (FOUCAULT, 2017, p.283/ DE, II, 1550) ${ }^{4}$, cabe-nos inicialmente dois questionamentos que serão os fios condutores deste texto: como a pesquisa foucaultiana poderia se desdobrar em uma inflexão estética que alcançaria o presente, sobretudo, se voltando para as vidas que são invisibilizadas, obscurecidas por discursos classificatórios, normativos e excludentes? Como é possível, a partir de existências mínimas, precárias, extrair a força que mobilizaria atitudes de resistência e transformação, rompendo os estratos de discursos infames sob os quais, muitas vezes, estão soterradas?

Antes de tentarmos responder a tais indagações a partir das reflexões investigativas de Foucault, vale aqui apontar como observação preliminar o fato de que perscrutar as "artes da existência" da Antiguidade, serviu a Foucault como

\footnotetext{
4 Toda vez que citarmos a coletânea Ditos e Escritos, compilação de textos e entrevistas de Michel Foucault, mencionaremos primeiro a referência da coleção brasileira, publicada pela Editora Forense Universitária e, logo em seguida, faremos a referência da coletânea francesa publicada pelo selo Quarto Gallimard, em acordo com a edição revisada no ano de 2017.
} 
um meio de aproximação de práticas que lhe concederam menos uma pesquisa que se centrasse na composição de singulares modos de vida a partir de regras e normas, do que encontrar aberturas históricas em que vidas puderam se transformar. Foucault indicou buscar, principalmente em suas últimas pesquisas, experiências outras em determinado contexto cultural que puderam favorecer a transformação de si, permitindo "modificar-se em seu ser singular", fazendo com que a própria existência fosse vista como obra dotada de valores estéticos que pudesse responder a "critérios de estilo" (FOUCAULT, 1984, p. 15).

Não é à toa que quando os comentadores Valério Marchetti e Antonella Salomoni remontam a situação do curso Os anormais, proferido entre janeiro e março de 1975, é ressaltado por eles um aspecto importante da trajetória foucaultiana e que acreditamos não se referir apenas aos exames médicos das primeiras décadas do século XIX ou aos manuscritos sobre as práticas de confissão e direção da consciência dos séculos XVII e XVIII, como no caso do curso em questão, mas o remetem a outras épocas e às possibilidades de transformação, a saber: "Foucault se afasta bruscamente do 'presente', que se mete na 'história', que volta subitamente ao 'presente"'. (MARCHETTI, SALOMONI apud FOUCAULT, 2013, p. 296). Quer dizer, Foucault realizaria um périplo de pesquisa em que à medida que se coloca em direção ao passado, não apenas volta outro como traz consigo a potência da abertura de virtualidades estéticas no que diz respeito à transformação das existências.

Todavia, faz-se necessário destacar que a estética da existência em Foucault, apesar de exigir do pensador um mer- 
gulho investigativo em outras épocas, se fez acompanhar pela imediatez de uma luta constantemente atualizada, diretamente envolvida em uma batalha ética dada no presente, depondo sempre contra o "governo da individualização" que se abate sobre as existências marginalizadas e segregadas. Em uma entrevista concedida a Dreyfus e Rabinow, em 1983, Foucault diz o seguinte sobre isso:

São lutas que questionam o estatuto do indivíduo: por um lado, afirmam o direito de ser diferente e enfatizam tudo aquilo que torna os indivíduos verdadeiramente individuais; por outro, atacam tudo aquilo que separa o indivíduo, que quebra sua relação com os outros, fragmenta a vida comunitária, força o indivíduo a se voltar para si mesmo e o liga à sua própria identidade de um modo coercitivo. (FOUCAULT apud DREYFUS; RABINOW, 2013, p. 277).

Desse modo, a arte em Foucault ganha uma dimensão ímpar na medida em que se desloca dos objetos e se infiltra em um contexto ético que pode propiciar transformações subjetivas, ao mesmo tempo que permite a restauração das relações comunitárias. A arte que faz brilhar os olhos de Foucault é a própria possibilidade de transformação das existências, fazendo-o apostar em um campo não convencional de abordagem estética:

O que me surpreende é o fato de que, em nossa sociedade, a arte tenha se transformado em algo relacionado apenas a objetos, e não a indivíduos ou à vida; essa arte é algo especializado ou feito por especialistas que são artistas. Entretanto, não poderia a vida de todos se transformar numa obra de arte? Por que deveria uma lâmpada ou uma casa ser um objeto de arte, e não a nossa vida? (FOUCAULT apud DREYFUS; RABINOW, 2013, p. 306) 
Ao que tudo indica, tratar a arte não somente voltada aos objetos, mas aos indivíduos e suas relações éticas, vai se colocar como um propósito invariável dentro do escopo das pesquisas foucaultianas de seu último período, sobretudo, o que se estende de meados da década de 70 até 1984, o ano de sua morte. Christian Laval também reconhece que o foco mais ativo do pensamento foucaultiano se daria certamente em uma "filosofia da experiência de alteração", quer dizer, em uma experiência em que podemos sair alterados, transformados, reconhecendo que "passar por esse tipo de experiência alteradora, seja sozinho ou com os outros, permanece para Foucault não apenas uma questão de prática, mas uma grade de inteligibilidade da história" (LAVAL, 2018, p.103).

Ainda na entrevista de 1983, concedida a Rabinow e Dreyfus, Foucault ao se diferenciar do existencialismo de Sartre ${ }^{5}$, expõe a ideia de uma experiência alteradora que é também criativa: "Não deveríamos referir a atividade criativa de alguém ao tipo de relação que ele tem consigo mesmo, mas relacionar a forma de relação que tem consigo mesmo à atividade criativa" (FOUCAULT apud DREYFUS; RABINOW, 2013, p. 306), retirando disso um notável efeito (prático): "a partir da ideia de que o eu não nos é dado, creio que há apenas uma consequência prática:

\footnotetext{
5 A discordância em relação ao filósofo Jean Paul Sartre no que diz respeito à criação estética consiste na pressuposição de que a dimensão da criatividade, ressaltada pelo existencialismo sartreano, dependeria em última instância de um retorno ao eu, ao verdadeiro eu. Em um primeiro momento, do ponto de vista teórico, Foucault ressalta o mérito de Sartre evitar a ideia do eu como alguma coisa previamente dada, dizendo que a única consequência prática aceitável dessa inferência seria o despertar da criatividade. Segundo Foucault, o problema de Sartre no campo estético é então se referir ao trabalho de criação artística como sendo subsidiário da autenticidade ou inautenticidade (FOUCAULT apud DREYFUS; RABINOW, 2013, p. 306).
} 
temos que nos criar a nós mesmos como uma obra de arte" (Idem).

No contexto geral de experiências transformadoras, podemos observar que as pesquisas foucaultianas vão desde a questão da loucura, do nascimento da clínica, passam pelo exame dos discursos, dissecam o poder disciplinar, questionam a noção de justiça, expõem as tramas do poder, destacam o nascimento da biopolítica e os meandros da governamentalidade, fazem uma genealogia minuciosa da sexualidade e, por fim, em seus últimos anos, acabam se detendo nas práticas de si da Antiguidade e nos rituais da confissão, mas, mesmo com todo este leque temático, tais pesquisas parecem ganhar unidade somente se tivermos como pano de fundo as possibilidades de transformação das subjetividades. Assim, com toda esta variação de um percurso filosófico singular, mais uma vez nas palavras de Laval, pode-se muito bem identificar "uma desconcertante e paradoxal continuidade, a da vontade de ser outro, uma determinação constante de tornar-se outro" (LAVAL, 2018, p. 105).

E é sob o panorama de uma estética da existência identificada na pesquisa foucaultiana, que aqui nos propomos a retraçar alguns aspectos de um caminho filosófico que o aproximou das vidas infames, em que o pensador ressaltaria dessas existências condenadas por discursos difamatórios o que "permite fugir das condições de possibilidade de uma época, o que traz em si pelo menos a virtualidade de um deslocamento, de uma modificação de um quadro, e do modo de vida, de uma transformação de si" (LAVAL, 2018, p. 109).

Uma vez reconhecendo a dimensão estética em Fou- 
cault vinculada à arte de existir, pretendemos então tecer um texto que também se componha com as considerações do filósofo da estética Étienne Souriau, trazidas no inquietante livro As Existências Minimas, de David Lapoujade, no aspecto de que através da arte se daria uma espécie de transformação, como se houvesse a "obrigação de deixar o velho homem para encontrar um novo homem" (SOURRIAU, 2009, p.208, tradução nossa). Diante disso, aqui abordaremos de que modo os dois pensadores franceses parecem confluir na mesma direção no que liga a arte às transformações de si, isto é, ambos elaboram uma compreensão da estética interseccionada aos modos de existência, buscando tematizar de que modo as vidas que mesmo privadas do direito de existir, podem ainda encontrar espaços para se transformarem e reinventarem.

\section{NO ENCALÇO DO RASTRO BRILHANTE DAS VIDAS PARALELAS}

Faz-se um traço importante no pensamento de Foucault seu interesse por aqueles que foram excluídos, invisibilizados, como uma forma de dar destaque às vidas obscurecidas que apenas foram iluminadas quando colocadas como alvos de discursos disciplinares, "reformadores", e que as tratavam como objetos condenáveis para corroborar e justificar saberes articulados com modelos normatizados de pensamento e conduta.

Com uma sensibilidade voltada para estas vidas obscurecidas, Foucault teve a ideia de publicar no final dos anos 70, pela editora francesa Gallimard, uma coleção que ganhou o título de "As Vidas Paralelas". Com o livro de lem- 
branças da hermafrodita Herculine Barbin, Foucault lança seu projeto editorial a partir de uma atenção especial despendida a essas existências:

Sei que as paralelas são feitas para se encontrarem no infinito. Imaginemos outras, que, indefinidamente, divergem. Nada de ponto de encontro nem de lugar para recolhê-las. Muitas vezes elas não tiveram outro eco senão o de sua condenação. Deveríamos apreendê-las na força do movimento que as separa; deveríamos encontrar o rastro instantâneo e brilhante que elas deixaram quando se precipitaram em uma obscuridade em que "isso não se conta mais" e em que toda a "fama" está perdida. Seria como que o avesso de Plutarco: vidas a tal ponto paralelas, que ninguém pode mais encontrá-las. (FOUCAULT, 1978)

Esta coletânea só contou com mais um texto, além de Herculine Barbin dite Alexina $B$, intitulado Le cercle amoureux d'Henri Legrand, no ano de 1979, organizado por Jean-Paul Dumont e Paul-Ursin Dumont, que apesar de não ter a apresentação de Foucault, participava do mesmo escopo de publicação: trazer à tona relato de vidas outras, singulares, que foram divergentes indefinidamente, sem comparação a nenhuma outra, ressaltando delas apenas seus rastros "instantâneos e brilhantes". Com um olhar singular para estas vidas ditas obscuras, tais "rastros" não deixaram de ser identificados por Foucault tanto no diário de Herculine, que cometeu suicídio após ser obrigada depois de um processo jurídico a adotar o gênero masculino, independentemente de sua vontade, como nos manuscritos do arquiteto Legrand, que escreveu mais de quinze mil páginas criptografadas em um código secreto que ele mesmo designou de "sânscrito", vindo a padecer por demência e paralisia geral no hospital psiquiátrico Ville-Évrard, na região de Paris.

Faz-se importante destacar que já na ocasião do curso 
Os anormais, no Collège de France, na aula de 8 de janeiro de 1975, Foucault assinalaria seu interesse por discursos que podem determinar a liberdade ou a condenação, e, no limite, a vida e a morte de alguém. Os discursos para os quais Foucault se volta nesta aula são aqueles que funcionam na instituição judiciária com o valor de discursos de verdade, e são considerados verdadeiros porque participam de um estatuto científico, são elaborados por autoridades no assunto, por peritos, por pessoas qualificadas pela instituição científica, legitimando a justiça ou as instituições reformadoras em seu direito de punir, de tratar, de orientar, de conduzir. Entretanto, esta relação entre verdade e justiça desembocaria em enunciados que, nas palavras de Foucault, "possuem o estatuto de discursos verdadeiros, que detém efeitos consideráveis e que têm, no entanto, a curiosa propriedade de ser alheios a todas as regras, mesmo as mais elementares, de formação de um discurso científico; de ser alheios também às regras do direito e de ser, no sentido estrito (...), grotescos”. (FOUCAULT, 2013, p. 11).

Isto é, o caráter grotesco ou ubuesco ${ }^{6}$ de tais discursos é bem observado por Foucault na medida em que geram efeitos muitas vezes devastadores em determinados modos de vida. Apesar de longa esta passagem de sua aula, é interessante apresentá-la por apontar precisamente como identifica a problemática dos discursos que marcam as existências condenadas:

grotesco ou, se quiserem, o ubuesco não é simplesmente uma ca-

6 Ubuesco é um termo utilizado na peça Ubu Rei, de A. Jarry, do final do século XIX, refere-se mais precisamente a um caráter caricato, grotesco, cínico, cruel da personagem Ubu Rei (FOUCAULT, 2013, p. 25). 
tegoria de injúrias, não é um epíteto injurioso, e eu não queria empregá-lo nesse sentido. Creio que existe uma categoria precisa; em todo o caso, dever-se-ia definir uma categoria precisa de análise histórico-política, que seria a categoria do grotesco ou do ubuesco. $\mathrm{O}$ terror ubuesco, a soberania grotesca ou, em termos mais austeros, a maximização do poder a partir da desqualificação de quem os produz: isso, creio eu, não é um acidente na história do poder, não é uma falha mecânica. Parece-me que é uma das engrenagens que são parte inerente dos mecanismos de poder. $\mathrm{O}$ poder político, pelo menos em certas sociedades, em todo caso na nossa, pode se atribuir, e efetivamente se atribuiu, a possibilidade de transmitir seus efeitos, e muito mais que isso, de encontrar a origem de seus efeitos num canto que é manifestamente, explicitamente, voluntariamente, desqualificado pelo odioso, pelo infame ou pelo ridículo. (FOUCAULT, 2013, pp. 11-12).

Todavia, estes discursos que se empreendem a partir do odioso, do grotesco, do ridículo, não deixariam de compor, segundo sua interpretação, apenas uma paródia, mesmo que considerados científicos e verdadeiros, perfazendo uma coligação direta entre a violência de um poder político - a quem interessa excluir, difamar, invisibilizar - às artimanhas do saber, revestindo de verdade um "discurso que é ao mesmo tempo estatutário e desqualificado" (FOUCAULT, 2013, p. 13).

Por conseguinte, na esteira de suas pesquisas sobre os discursos que versariam sobre o domínio da anomalia, discursos que criaram os monstros humanos, os desviantes sexuais, tais como a criança masturbadora, o indivíduo a ser corrigido, Foucault, em 1978, à época da elaboração da coleção Vidas Paralelas, passa então a se direcionar para os próprios textos dos infames, não os retendo como um relato de vidas exemplares, como em Plutarco, nem muito menos como monstros de acordo com o que designava os 
relatórios médico-legais. Com outra perspectiva, a questão para Foucault é tratar de vidas que não se cruzariam com nenhuma outra dada sua trajetória divergente, retendo delas apenas a "força do movimento" que as separaria das demais existências, permitindo-se seguir seus vestígios, mesmo que "instantâneos e brilhantes", quando precipitadas na obscuridade infinita.

É importante destacar que Foucault publica em 1977 um artigo intitulado $A$ vida dos homens infames, nos Cahiers $d u$ Chemins, no qual trata de dizer o porquê de querer publicar relatos, notícias, documentos de vidas ínfimas que foram sufocadas por instituições ou práticas políticas. Neste texto são citadas por Foucault duas pequenas notícias que o despertaram em apresentar a vida desses homens considerados "infames". Estas notas foram encontradas em uma pesquisa na Biblioteca Nacional da França $(B n F)$, quando passou os olhos pelos registros de internação e de prisão do início de século XVIII; o primeiro relato a despertar sua atenção foi de um homem chamado Mathurin Milan, internado no hospital de Charenton, em 1707, em que o consideraram louco por se esconder da família, emprestar dinheiro a fundo perdido, levar uma vida errante, e "acreditar-se capaz de maiores trabalhos"; a segunda notícia foi do frade Jean-Antoine Touzard, preso no Castelo de Bicêtre, em 1701, acusado de ser um monstro abominável e um ateu pela sua prática da sodomia.

A partir destes casos e de outras notícias, Foucault diz sobre seu interesse desde A História da loucura de escrever uma antologia desses documentos, o que nunca se efetivou, mas, de qualquer forma, tais relatos o afetaram, como ele 
mesmo expressaria neste artigo, por sentir uma vibração especial "ao encontrar essas vidas ínfimas que se tornaram cinzas nas poucas frases que as abateram", provocando-o a uma virada "metodológica":

$\mathrm{Na}$ falta do talento necessário, por muito tempo remoí só a análise; tomei os textos em sua aridez; procurei qual tinha sido sua razão de ser, a quais instituições ou a qual prática política eles se referiam; propus-me a saber por que, de repente, tinha sido tão importante em uma sociedade como a nossa que um monge escandaloso ou um agiota extravagante e inconsequente fossem "sufocados" (como se sufoca um grito, um fogo ou um animal) (FOUCAULT, 2006, pp. $204-$ 205/DE, II, p. 238).

Os discursos sobre os quais passa a mostrar interesse são justamente os fragmentos de uma realidade em que muitos destinos de vidas reais foram decididos por palavras: "Esses discursos realmente atravessaram vidas; essas existências foram efetivamente riscadas e perdidas nessas palavras". Nesta proposta de pesquisa em que se detém a ressaltar os infames e anormais, Foucault parece querer restituí-las de uma dignidade roubada pelos discursos condenatórios, por isso traça algumas regras "simples" que queria seguir a partir de então, tais como: 1. que se tratasse de personagens que tivessem realmente existido; 2 . que essas existências fossem "obscuras e desventuradas"; 3. que fossem contadas apenas em algumas frases, trechos breves; e, por fim, acrescenta: "que esses relatos não constituíssem simplesmente historietas estranhas ou patéticas, mas que de uma maneira ou de outra (porque eram queixas, denúncias, ordens ou relações) tivessem feito parte realmente da história minúscula dessas existências, de sua desgraça, de sua raiva ou de sua incerta loucura”, precisando daí sua intenção: para que "do 
choque entre as palavras e estas vidas pudesse surgir um efeito de beleza e de terror" (FOUCAULT, 2006, pp. 205. 206/DE, II, p. 239).

Banindo o que pudesse ser "imaginação ou literatura", Foucault ressalta o encontro dessas vidas infames com o poder: "poder que espreitava essas vidas, que as perseguiu, que prestou atenção, ainda que por um instante, em suas queixas e em seu pequeno tumulto, e que as marcou com suas garras" (FOUCAULT, 2006, p. 207/DE, II, p. 240). Neste sentido, o poder identificado pelo pensador encobriria tais indivíduos em uma atmosfera obscura, prevalecendo sobre os erros comuns um clamor de cólera. Este poder pontuado pelo pensamento foucaultiano era, portanto, exercido por instituições reformadoras, médicos, peritos, policiais, juízes que detinham atenção especial em alguns casos, concedendo-lhes um brilho mórbido, a exemplo do "monge escandaloso", do "bêbado inveterado e furioso", do "vendedor brigão", e "não tanto outros, ao lado destes, cujo barulho não era menor" (FOUCAULT, 2006, pp. 209. 210/DE, II, p. 242).

Estes seres infames, segundo a leitura de Foucault, passam então a sobreviver do choque com um poder que os encerra em um discurso, através das "poucas palavras terríveis que eram destinadas a torná-los indignos para sempre da memória dos homens" (FOUCAULT, 2006, p. 210/DE, II, p. 243). Assim, Foucault destacaria a mesma visão já elaborada no curso Os anormais, dois anos antes da escrita deste artigo, por apontar que apesar destas palavras terríveis serem ácidas, duras, aviltantes, há um "efeito cômico" nelas, pois algo de irrisório, de grotesco, de ubuesco, se enunciaria no exagero das palavras, nas execrações ou nas ênfases 
empregadas mesmo diante das situações mais banais, ressaltando-se com isso uma retórica que muito se aproximaria da "grandiloquência" se não fosse pela "pequenez das coisas" às quais se aplicava.

Diante disso, consideramos ser um caráter marcante do pensamento foucaultiano destacar um tipo de poder que se empreenderia na captura das vidas consideradas obscuras pelo uso de termos desmedidos, jocosos, em que as palavras ressaltariam sobremaneira o brilho das decisões que foram impostas a essas existências, cravando-se na pele dos homens ditos infames a imagem de verdadeiros monstros. Foucault se indaga: quais realmente são os motivos "desse teatro tão enfático do cotidiano"? Para a resposta, ele apresenta em uma breve genealogia de como a partir do ritual da confissão teria vindo à tona um modo de dispor a linguagem a serviço da obrigação de tudo dizer. Vejamos:

Obrigação de fazer passar regularmente pelo fio da linguagem o mundo minúsculo do dia-a-dia, as faltas banais, as fraquezas mesmo imperceptíveis, até o jogo perturbador dos pensamentos, das intenções e dos desejos; ritual de confissão em que aquele que fala é ao mesmo tempo aquele de quem se fala; apagamento da coisa dita por seu próprio enunciado, mas aumento igualmente da própria confissão que deve permanecer secreta, e não deixar atrás de si nenhum outro rastro senão o arrependimento e as obras de penitência (FOUCAULT, 2006, pp. 212-213/DE, II, p. 245).

Ou seja, através da confissão, Foucault identifica que o Ocidente cristão teria inventado uma maneira surpreendente de poder coagir as pessoas, impondo a cada um a obrigação de falar tudo, exaustivamente, nada devendo escapar, instaurando-se assim um contexto linguístico-moral que perpassou muitos séculos, em que o "mal teve de se 
confessar na primeira pessoa, em um cochicho obrigatório e fugidio" (FOUCAULT, 2006, p. 213/DE, II, p. 245). Segundo a genealogia foucaultiana, no final do século XVII, a confissão passa a ter outro funcionamento do que o religioso, mediado desde então em um contexto administrativo, tal prática não serviria apenas para conceder perdão, mas, sobretudo, para registrar as irregularidades e desordens da vida das pessoas. Comenta assim sobre o novo "enquadramento" da confissão que vai surgir na modernidade:

se utilizam, e sistematicamente, procedimentos antigos, mas, até então, localizados: a denúncia, a queixa, a inquirição, o relatório, a espionagem, o interrogatório. E tudo o que assim se diz, se registra por escrito, se acumula, constitui dossiês e arquivos. A voz única, instantânea e sem rastro da confissão penitencial que apagava o mal apagando-se ela própria é, doravante, substituída por vozes múltiplas que se depositam em uma enorme massa documental e constituem assim, através dos tempos, como a memória incessantemente crescente de todos os males do mundo. $\mathrm{O}$ mal minúsculo da miséria e da falta não é mais remetido ao céu pela confidência apenas audível da confissão; ele se acumula sobre a terra sob a forma de rastros escritos. É um tipo de relações completamente diferentes que se estabelecem entre o poder, o discurso e o cotidiano, uma maneira totalmente diferente de o reger e de o formular. Nasce, para a vida comum, uma nova mise en scène (FOUCAULT, 2006, p. 213/DE, II, pp. 245-246).

Nesta mise en scène em que se estabelece relações entre poder, discurso e cotidiano, Foucault identificou um sistema que durou pouco mais de um século na França designado de lettres de cachet, constituído de um conjunto de documentos com o selo do rei escritos para expressar as ordens de prisão-internamento, sem direito a julgamento prévio. Portanto, com as lettres de cachet, Foucault vê nascer "uma infinidade de discursos que atravessa o cotidiano em 
todos os sentidos, e se encarrega, mas de um modo absolutamente diferente da confissão, do mal minúsculo das vidas sem importância” (FOUCAULT, 2006, p. 216/DE, II, p. 248). Neste contexto começam a se estabelecer circuitos complexos em que as redes de poder vão se ocupar do "mal minúsculo", em um "imenso e onipotente apelo" de apresentá-los em discurso, tais como brigas de casal, confusões entre os vizinhos, bebedeiras, orgias sexuais, jogatina etc.

A partir destes textos percebe-se então um uso desmedido entre o caráter trivial e pequeno dos problemas e o furor do poder aplicado, ao relatar, comenta Foucault, "toda uma 'baixeza' como se dizia, que nenhuma literatura nessa época teria podido acolher" (FOUCAULT, 2006, p. 218/DE, II, p. 250). No entanto, esta desproporcionalidade entre o fato insignificante e o discurso grave a ele emitido vai diminuindo à medida que o poder monárquico, "todopoderoso e caprichoso" e "fonte de toda justiça", vai ser substituído por um poder complexo, disposto em uma microfísica, ou seja, em uma rede contínua e vascularizada, onde se alternariam as instituições de controle fazendo valer uma normatização das condutas.

Toda mise en scène criada pelos discursos das lettres de cachet para dizer sobre o banal será então substituída na passagem do século XVII para o XVIII pela "grelha eficaz mas cinza da administração, do jornalismo e da ciência” (FOUCAULT, 2006, p. 219/DE, II, p. 250), surgindo outra maquinaria entre o poder, os discursos e a vida cotidiana, como Foucault salienta, em que também a literatura estaria engajada. Se antes havia a predominância literária do fabuloso - a fábula etimologicamente refere-se àquilo que merece ser dito -, em que o cotidiano aparecia primei- 
ramente como encoberto pela atmosfera fabulosa, fazendo jus a um discurso em que se ressaltaria as tintas mais decorativas sobre os fatos, verdadeiras composições rocambolescas para tratar da banalidade do cotidiano, já com o poder infiltrado na rede fina das relações humanas, pouco a pouco, o gênero fabuloso das narrativas vai se transformando em discursos objetivos e realistas. Recobre-se daí os fatos com a crueza de se dizer sobre o "mais difícil de perceber, o mais escondido, o mais penoso de dizer e de mostrar, finalmente o mais proibido e o mais escandaloso" (FOUCAULT, 2006, pp. 220-221/DE, II, p. 252).

Este modo de descrever "realisticamente" os fatos, de ir buscá-los em sua brutalidade concreta, começa por empreender uma série de imposições para observar e disso reter o lado obscuro e cotidiano das existências. Foucault, em decorrência de sua pesquisa, afirma que a literatura - porque não dizer as artes na forma geral de sua expressão - não deixaria de compor um "grande sistema de coação através do qual o Ocidente obrigou o cotidiano a se pôr em discurso”, vindo então a ocupar um lugar especial:

obstinada em procurar o cotidiano por baixo dele mesmo, em ultrapassar os limites, em levantar brutal ou insidiosamente os segredos, em deslocar as regras e os códigos, em fazer dizer o inconfessável [...]. Mais do que qualquer outra forma de linguagem, ela permanece o discurso da "infâmia": cabe a ela dizer o mais indizível - o pior, o mais secreto, o mais intolerável, o descarado (FOUCAULT, 2006, p. 221/DE, II, pp. 252-253).

Esta forma literária de dizer sobre as vidas consideradas marginais provoca assim uma espécie de limitação da "realidade" da qual participam tais existências, pois as encerram nos discursos da infâmia. Daí surge uma questão que pare- 
ce ser o pano de fundo da visada estética de Foucault: como ainda poder redizer estas existências quando são apropriadas por um discurso que as comprime em uma realidade prefigurada? Como restituí-las em seu caráter amplo das possibilidades artísticas de existir?

\section{FOUCAULT E SOURIAU: FILÓSOFOS-ARTISTAS DAS EXISTÊNCIAS MÍNIMAS}

Étienne Souriau (1892-1979) foi um filósofo do campo das artes, que se dedicou não apenas à estética, como também a questões de filosofia pura e das existências individuais. David Lapoujade, em seu livro As Existências Mínimas, se detém, a partir da obra de Souriau, a tratar das existências que teriam sua potência de ser mitigadas por uma privação do direito de existir. Sob o olhar de Lapoujade, a obra Les Différents modes d'existence, de Souriau, traria uma compreensão estética importante que incidiria diretamente na relação com modos de existir. Isto é, Souriau teria o mérito de reconhecer uma potência de transformação pela arte, mesmo quando relacionada às existências mínimas, sendo tal reconhecimento tributário do seu estudo sobre a "variedade infinita dos modos de existência”?

Sendo assim, para Souriau, a arte seria uma atividade instauradora. Nas suas próprias palavras, a arte é um "con-

\footnotetext{
7 Para Souriau, cada modo de existência deve ser visto como uma arte de existir. Dessa forma, como explica Lapoujade, "o modo não é uma existência, mas a maneira de fazer existir um ser em determinado plano". Diante disso, o modo se vincula à existência a partir dos limites dos seres (LAPOUJADE, 2017, p.15).
} 
junto de ações orientadas e motivadas, que tendem expressamente a conduzir um ser", esta condução perfaz uma miríade de possibilidades que vai "do nada ou de um caos inicial até a existência singular, concreta que se atesta em presença indubitável." (SOURIAU, 1983, p.35).

Todavia, uma questão se faz presente, quer seja: no caso de vidas precárias, de que forma os diversos modos de existir podem ser alçados à realidade em situações em que as vidas são tomadas de assalto por um poder que as captura e limita? Lapoujade, inspirado pela obra de Souriau, apreende uma espécie de ontologia das condições de existência, considerando cada modo singular de expressão "por si só uma arte de existir". Assim sendo, o modo de existência dependeria, em última instância, de um gesto instaurador (LAPOUJADE, 2017, p. 15).

Com esta perspectiva, cada existência se vincularia grosso modo a um ato que pudesse instaurá-la, sendo este gesto imanente a cada existir. A tarefa filosófica ficaria então na incumbência de explorar a variedade dessas possibilidades de existência, considerar portanto não só um mundo de obscuridade, mas o que ele traz de indefinido e de nada, no qual se esboçam os modos de existir, na medida em "que conquistam paulatinamente sua realidade" (LAPOUJADE, 2017, p. 18). Neste sentido, na interpretação de Lapoujade, a filosofia de Souriau ao deter seu olhar para as existências mínimas pretendeu, em suas linhas gerais, "percorrer as nuances da existência” (LAPOUJADE, 2017, p.21), ou seja, "explorar toda uma variedade dos modos de existência compreendidos entre o ser e o nada" (idem).

Já com Foucault, pelos desdobramentos de sua posição 
ética de trazer à tona a impropriedade dos discursos voltados às vidas dos infames, podemos depreender que tenha traçado uma trajetória análoga à de Souriau, quando se volta também neste passo inusitado de percorrer os rastros dos modos de existir. Se há filósofos que se fazem legisladores, juízes, pedagogos, Foucault, assim como Souriau, ao que tudo indica, fizeram um caminho singular ao vislumbrarem por trás de pessoas reais as figuras estéticas, as "personagens" construídas em uma dimensão jurídica, ou por que não dizer, por uma ordem de discurso normativa.

Como Lapoujade salienta, se Souriau se ocupa sobretudo da estética não é para fazer apagar as características jurídicas em prol da estética (LAPOUJADE, 2017, p. 22), mas, ao contrário, para fazer ver, denunciar, como algumas existências obscuras, em seus contornos estéticos, seriam dependentes de uma dimensão jurídica, de um discurso institucionalizado que as prenderia em determinada "imagem”. Não seria diferente o propósito de Foucault.

Não é sem imprimir uma dimensão crítica a uma ordem de discurso, que também Souriau concederia na esteira de suas considerações sobre as existências individuais uma extraordinária funcionalidade para duas figuras jurídicas, a saber, da testemunha e do advogado, colocando-as agora a serviço das existências mínimas. Diante dessas considerações de Souriau, depreendemos que tais figuras (testemunha e advogado) bem poderiam ser identificadas no modo foucaultiano de abordar as vidas infames, no sentido de que através das palavras de Foucault, da intensidade com que grifa determinados textos e palavras acusatórias, pudesse evidenciar as maquinações do poder que mitigaram as possibilidades de existência dessas pessoas consideradas 
marginais.

Isto é, o pensamento de Foucault e de Souriau se encontrariam em um aspecto importante, a saber, na produção de um contra efeito a partir do próprio discurso jurídico, ambos exercendo o papel tanto de testemunhas como de advogados dos modos singulares de viver, subvertendo o discurso jurídico através dele mesmo ao expor a arbitrariedade do uso de palavras que limitam ou anulam o direito de existir de vidas condenadas.

Sumariamente, podemos então considerar que a figura da "testemunha", que nos inclinamos em identificar na visada de Foucault relacionada aos homens infames, é aquela erguida por um pensador que também enfrenta a contrapelo os discursos de sua época em nome da memória de existências violentadas e invisibilizadas. Sua percepção singular, portanto, destituída de neutralidade e de imparcialidade, teria uma força criativa na medida em que

Certas percepções privilegiadas suscitam o desejo de testemunhar "a favor" da importância ou da beleza do que elas viram. Nesse caso, perceber não é simplesmente apreender o que foi percebido, é querer testemunhar ou atestar seu valor. A testemunha nunca é neutra ou imparcial. Ela tem a responsabilidade de fazer ver aquilo que teve o privilégio de ver, sentir ou pensar. Ela se torna um criador. De sujeito que percebe (ver), torna-se sujeito criador (fazer ver). (LAPOUJADE, 2017, p. 22)

No entanto, Lapoujade considera que para a conquista de um direito de existir, obviamente influenciado por Souriau, surgiria a reboque da testemunha a figura emblemática do advogado. Ora, é o advogado que convoca a testemunha, "quem faz com que toda a criação se torne um discurso de defesa a favor das existências que ela faz aparecer, ou 
melhor, comparecer" (LAPOUJADE, 2017, p. 22). Destarte, o advogado, em seu propósito de ressaltar as vidas infames e desafortunadas, de torná-las mais reais pelo gesto de trazê-las a um plano de destaque, é capaz também de produzir novas realidades, "onde antes ninguém tinha visto nada, imaginado nada” (LAPOUJADE, 2017, pp. 22-23).

Não seria a missão foucaultiana de seguir os rastros instantâneos e brilhantes das existências obscuras uma forma de exercer tanto a função de testemunha quanto a de advogado perante essas vidas? O próprio Souriau parece confirmar essa hipótese, quando diz em Os Diferentes modos de existência, que "Instaurar é seguir um caminho. Nós determinamos o ser a surgir ao explorar o seu caminho" (SOURIAU, 2009, p. 208, tradução nossa). Vencendo todo um discurso de negação que contesta o direito de existir dos infames, Foucault parece então conferir legitimidade a estas existências divergentes à medida que a partir de seus rastros, por seguir seus caminhos, é, portanto, capaz de confirmá-las na pluralidade de ser.

Mas, oportunamente, Lapoujade se indaga: seria possível "uma existência conquistar por ela mesma sua legitimidade?" e "como tornar as existências mais reais?" (LAPOUJADE, 2017, pp. 24-25). Talvez estas indagações possam ser respondidas de uma única forma: as existências se tornam "mais reais" na medida em que se vinculam eticamente a outros que possam reconhecê-las, empreendendo uma espécie de "subordinação arquitetônica". Na tentativa de explicar esta relação, Souriau diz que na subordinação arquitetônica a correlação dos elementos muda, por exemplo: 
Os músicos vão entender o que é, quando pensarem em uma "modulação enarmônica": esta sucessão de dois acordes feitos substancialmente das mesmas notas, mas cuja sucessão efetua uma mudança de tom, porque a nota que soou como tônica no primeiro, agora soa como dominante ou como sensível, etc; e que desta forma todo o equilíbrio interno é modificado caleidoscopicamente, sem modificação dos termos. (SOURIAU, 2009, p.148, tradução nossa).

Sendo assim, há um aspecto ético em Foucault importante de se grifar, que se daria na relação entre as existências, como se a partir desse vínculo houvesse uma "legitimação" dos modos de existir. Esta legitimação - que para Souriau adquire uma forma estética, e não jurídica - também parece se apresentar na obra foucaultiana. Sendo assim, sob um ponto de vista a um só tempo ético e estético, a possibilidade de novos modos de existir se relacionaria à condição de vidas vinculadas em uma atitude de reconhecimento, uma fazendo ver a outra a partir dos traços e estilos que a comporiam singularmente.

Isto é, ao se deter em vidas paralelas não querendo mais remoer apenas análises, nem com o propósito de julgá-las ou condená-las, mas de dar vazão às vozes que foram sufocadas, Foucault de alguma forma se apresenta como um intensificador dessas vidas, como aquele que as reconhece para além dos discursos que as capturam, fazendo-as conquistar o brilho de existirem. Diante disso, uma pergunta se faz oportuna, e Lapoujade a pontua: será que exercer esta função de intensificador de outras existências, assumindo o papel de testemunha e advogado, significaria também "lutar por novos direitos"? (LAPOUJADE, 2017, p. 25) Lapoujade ultrapassa este questionamento quando lança uma hipótese indagativa, considerando que talvez muito mais do que uma questão de direito fosse uma questão de arte, em que 
através de gestos instauradores tais existências conseguissem "se colocar legitimamente".

Se olharmos com cuidado o propósito de Foucault em tratar de vidas infames ou dos anormais, podemos reconhecer uma abordagem dessas existências que escapa da atitude de lutar por novos direitos, e talvez isso se dê por entender que enquanto os sujeitos são colocados em relações de significação, mesmo que seja a pretexto de lhes garantir novos direitos, se cai em relações de poder que são muito complexas. Assim, no decorrer de sua obra, Foucault vai se esquivando de uma reivindicação de direitos, talvez por compreender que a reboque do direito se desenvolvem dispositivos que objetivam o sujeito (FOUCAULT apud DREYFUS; RABINOW, 2013, p. 273), em que as regras do direito acabam servindo a uma "delimitação formal do poder" (FOUCAULT, 1980, pp. 92-93), suscetíveis portanto de produzir discursos identitários que capturam as existências. Neste sentido, entendemos que qualquer luta por direitos deve ser vista com reserva na produção foucaultiana, pois, sob o domínio da lei, o direito se torna um agente permanente de técnicas polimorfas de subjugação, por isso o pensador assevera: "o direito deve ser visto [...] não em termos de uma legitimação a ser estabelecida, mas em termos dos métodos de subjugação que instiga" (FOUCAULT, 1980, p. 96).

Já no que se refere à arte, como gesto capaz de legitimar existências, tudo indica que aí possamos reconhecer o lugar de Foucault diante das vidas obscuras. Souriau, no intuito de fundamentar uma arte capaz de instaurar existências, apresenta um universo que lhe parece ser muito caro na possibilidade de reconhecimento das vidas mínimas, a saber, os 
virtuais. $\bigcirc$ filósofo da arte define os virtuais como "uma quantidade de esboços ou de começos" que são capazes de desenhar, em uma realidade que é "minúscula e mutante", um "jogo caleidoscópico de seres que nunca existirão" (SOURIAU, 2009, p. 136, tradução nossa).

Entretanto, é importante esclarecer que "seres nunca existirão" porque não se esgotam suas possibilidades de existência na realidade. Ainda em Os Diferentes modos de existência, Souriau esclarece o seguinte sobre a questão dos virtuais e a possibilidade da existência efetiva das coisas:

Dizer que uma coisa existe virtualmente, isto quer dizer que ela não existe? De modo nenhum. Mas isso não diz nada mais que ela é possível. Significa dizer que qualquer realidade a condiciona, sem compreendê-la ou postulá-la. Ela (a existência das coisas) se completa, se fecha no vazio do puro nada. O arco da ponte quebrada, ou iniciada, virtualmente atrai a precipitação que está faltando. A curva das vigas interrompidas, no topo das colunas, mostra no vazio a pedra angular que faltava. A curva incipiente de um arabesco representa virtualmente todo o arabesco. (SOURIAU, 2009, p. 136, tradução nossa)

Lapoujade nos auxilia também na compreensão deste modo de existência vislumbrado por Souriau e que também pode se aproximar do propósito foucaultiano no tratamento das vidas infames:

Os virtuais estão aí, à nossa volta, eles aparecem, desaparecem, se transformam, à medida que a própria realidade muda: eles não têm nenhuma solidez, nenhum lugar determinado, nenhuma consistência. Por um lado, é o universo mais amplo e mais rico - pelo menos na aparência - mas também é o mais evanescente, o mais inconsistente, o mais próximo do nada. (LAPOUJADE, 2017, p. 38)

Os virtuais tem assim um "estatuto à parte", em que apenas a "arte", arte de reconhecimento, teria o poder de 
delinear uma perfeição no modo de ser, uma perfeição encontrada na condição de inacabamento das existências, ou seja, é como se houvesse no reconhecimento desta nuvem de virtuais que compõem todas as existências sempre uma expectativa de que algo pudesse ser ainda realizado. Portanto, é por isso que estão "à parte", pois "esperam a arte que pode lhes dar uma existência maior e diferente. Sua arte é suscitar ou exigir a arte; seu 'gesto' próprio é suscitar outros gestos. Eles precisam de outro ser - um criador - que agirá para que possam ter uma existência maior e diferente" (LAPOUJADE, 2017, p. 38).

Do lado do criador, daquele em que a partir de seu gesto traz à tona existências com todas as suas possibilidades, o universo de virtuais permite a produção de novas realidades, introduzindo um desejo de criação, "uma vontade de arte no mundo". Desse modo, toda realidade está envolta por um plano de potencialidades, em que "cada existência pode tornar-se uma incitação, uma sugestão ou germe de outra coisa, o fragmento de uma nova realidade futura" (LAPOUJADE, 2017, p. 39).

\section{CONSIDERAÇÕES FINAIS}

Foucault parece encontrar nestas existências mais frágeis, próximas do nada, uma força de torná-las mais reais na medida em que sendo capaz de percebê-las em seu rastro brilhante, abriria todo um leque de possibilidades de elas existirem amplamente. Ao pretender romper os limites de práticas classificatórias e excludentes, a atenção dada pelo pensamento foucaultiano a vidas paralelas é eficiente em restituí-las na possibilidade de existirem "outramente", im- 
plicando sua estética da existência a uma luta contra as representações rígidas impostas às pessoas. Assim, tal luta travada em defesa de existências mínimas parece encontrar seu apoio em torno da questão “quem somos nós?", fazendo dessa indagação filosófica, por um lado, uma recusa das abstrações de um discurso científico ou administrativo que determina quem somos, e, por outro lado, um combate estratégico do estado de violência econômica e política que nos invisibilizam, ignorando irremediavelmente quem somos e corroendo as possibilidades do que ainda poderemos ser.

É como se Foucault visse nestas vidas sujas, manchadas, no momento em que caem sob sentenças discursivas, ainda se apresentar a partir delas um campo de potencialidades, de criações. Neste aspecto, Foucault andaria lado a lado com o filósofo da estética Étienne Souriau, pois para ambos a estética ligada às existências mínimas se vincularia a uma aposta de constituirmos novas arquiteturas subjetivas, sendo que a arte estaria "na captação e composição de heterogêneos, em vez de caminhar, interminavelmente, para a suposta essência” (LAPOUJADE, 2017, p. 117).

É importante pontuar, a título de conclusão, que a estética para Souriau implica um duplo movimento; tanto de ressaltar a queda das existências no momento em que haveria o encontro com a dimensão catastrófica (o prefixo kata designa algo que sucede de cima para baixo), como também anafórico, que nos remeteria a um evento que vai do ponto zero a uma espécie de sublevação existencial. Este manejo oriundo de uma estética vinculada às existências propiciaria "uma maneira de limpar a percepção, de lavar os olhos para reencontrar a força de ver e de fazer ver" (LAPOUJADE, 
2017, p. 116), ou, noutros termos, esta "força de ver e de fazer ver" se entrelaçaria intimamente com a própria arte de viver. Como diz Souriau, a estética voltada à existência permite então evocar "uma arte mais direta, mais íntima, mais imediata, mais humana, mais preciosa talvez, ainda que mais difícil, e que não seria outra senão a arte de viver." (SOURIAU, 1983, p. 270)

Nesta "arte de viver", diante de uma situação catastrófica que pode atingir qualquer vida, é possível então se destacar um ponto de "conversão do limite". Neste contexto, fazer ouvir as vozes dos homens infames, dar crédito à sua polifonia, aos seus ruídos em suas catástrofes pessoais, é também poder borrar a fronteira entre o são e o louco, entre o criminoso e os que seguem as leis, apresentando-os apenas em acordo com os tons de suas modulações existenciais. Podemos considerar que o processo de elaboração ou produção da arte que Souriau nos apresenta é o momento em que, do encontro com as catástrofes existenciais, pode-se empreender uma inversão interessante da queda para elevação, no sentido de que se "possa admitir novas entidades, para capturá-las no momento da sua aparição ou do seu desaparecimento" (LAPOUJADE, 2017, p. 117).

Souriau afirma, em seu livro A Correspondência das artes - Elementos de estética comparada, que a amplitude da arte, seu movimento mais interessante, estaria na sua força de "forjar um caráter, fortificar uma alma, levar o ser humano ao pleno desabrochar de sua existência pessoal. (SOURIAU, 1983, p.42). Sendo assim, Lapoujade, sobre o processo criativo na arte em seus caminhos complexos, referindo-se às possibilidades do desabrochar das existências, diz o seguinte: "Os momentos mais emocionantes para 
Souriau são aqueles em que surge uma nova existência, como se ela tivesse saído de uma bruma, e cuja realidade é preciso aumentar" (LAPOUJADE, 2017, p.117).

Diante disso, depreendemos que o que parece importar a Souriau não deixa de se apresentar no pensamento de Foucault: ambos os filósofos se encontram quando tratam das existências singulares a partir das variações dos diversos modos de ser, das modulações em que vibram as vidas infames; contínuo movimento de aparecer e desaparecer, em que tanto se escapa do aprisionamento de estereótipos paralisantes, como se abrem novas chances para as potências imprevisíveis de sermos outros.

Abstract: This article seeks, based on Michel Foucault's considerations, the dimension of an aesthetic of existence to relate it to infamous lives, in two planes that seem to be linked, namely, first, to highlight the obscure lives that were only illuminated when placed as objectives of the speeches made for the purposes of classification, control and exclusion; second, the possibility of transformative experiences in relation to marginalized subjectivities. We will examine the extent to which Foucault's research would lead to the virtuality of an aesthetic and ethical displacement, of the modification of a way of life, of a style of existence. After recognizing the aesthetic dimension in Foucault linked to the art of existing, we intend to weave a text that is also composed of considerations about the aesthetics of the philosopher Étienne Souriau, presented in the book Les Existences Moindres, by David Lapoujade, in the sense that two French thinkers seem to converge in the same direction, which links art to the transformations of the self, that is, both elaborate an understanding of aesthetics crossed with modes of existence, seeking to reflect how the lives deprived of the right to exist, could still find spaces for creation and transformation.

Keywords: Art; Minimal existence; Transformations of the self; Lifestyle.

\section{REFERÊNCIAS}

\section{DREYFUS, H e RABINOW, P. Michel Foucault: uma}


trajetória filosófica. $2^{\text {a }}$ edição. Rio de Janeiro: Forense Universitária, 2013.

FOUCAULT, M. Herculine Barbin dite Alexina B. Présentée par Michel Foucault. Paris: Gallimard, 1978.

. Power/Knowledge: selected writings, interviews \& other writings - 1972-1977. Edited by Colin Gordon. New York: Pantheon Books, 1980.

. História da Sexualidade 2: o uso dos prazeres. 1. Ed. Rio de Janeiro: Edições Graal, 1984.

- A vida dos homens Infames. In: Ditos e Escritos. Vol. IV: Estratégia, Poder, Saber. $2^{\mathrm{a}}$ edição. Rio de Janeiro: Forense Universitária, 2006.

. Os Anormais: curso no Collège de France (19741975). São Paulo: Editora Martins Fontes, 2013.

- $O$ sujeito $e$ o poder. In: DREYFUS, $\mathrm{H}$ e RABINOW, P. Michel Foucault: uma trajetória filosófica. 2. Ed. Rio de Janeiro: Forense Universitária, 2013.

Gallimard. 2017.

. Dits et écrits, II (1976-1988). Paris: Quarto - Uma estética da existência. In: Ditos e Escritos. Vol. V: Ética, Sexualidade e Política. 3. Ed. Rio de Janeiro: Forense Universitária, 2017.

LAPOUJADE, D. As Existências Minimas. São Paulo: N1 edições, 2017.

LAVAL, C. Foucault e a experiência utópica. In: FOUCAULT, M. O enigma da Revolta: entrevistas inédi- 
tas sobre a revolução iraniana. São Paulo: N-1 edições, 2018.

SOURIAU, É. A correspondência das artes - Elementos de Estética Comparada. São Paulo: Editora Cultrix, 1983. . Les différents modes d'existence. Paris: PUF,2009. 
